\title{
Evaluating Science
}

\author{
J. T. Trevors
}

Published online: 6 November 2010

(C) Springer Science+Business Media B.V. 2010

Evaluating scientific research at the proposal application stage, paper submission stage, and then postpublication is a challenging task that has come under increasing pressure to demonstrate the value of science to humanity, economic growth through innovation, and $\mathrm{R}$ and $\mathrm{D}$. In many countries, a significant amount of research is conducted at universities that are supported by the public through their tax contributions. Some research is also funded through industrial contracts and charities. The public has some say in how public funds are used for research at stakeholder meetings and in the choices they make for politicians and their platforms during elections. The public generally expects a return on their taxes invested in research, but this is an extremely difficult activity to measure.

At the individual researcher level, evaluations are conducted on the quantity and quality (but not always) of the research publications, patents, individual $h$ values, the number of graduate students completing their degrees annually, the training of research associates and postdoctoral fellows, equipment infrastructure brought into the department or college, and the amounts of research grants over many years. This measures individual and research team progress by counting inputs and outputs, but it

J. T. Trevors $(\bowtie)$

School of Environmental Sciences, University of Guelph,

Guelph, Ontario, Canada N1G 2W1

e-mail: jtrevors@uoguelph.ca does not necessarily measure what counts as significant research for science and humanity. The easiest approach is simply to estimate activities rather than measure what is significant science. It is no surprise that some useless science has been funded and continues to be funded. The counterargument to this statement is that the research may be useful in the future in ways that cannot be known at this time. It is a small piece of a bigger puzzle or solution. Or the counterargument may be that all basic research is important and should be supported. The reality is that a balance must be achieved between the basic research that should be conducted and what strategic research should be conducted. Peer reviewers and committees that are involved in the evaluations of the proposed research do not necessarily arrive at the correct funding decisions. And so some research of no value to science and humanity will continue to be funded and conducted. This is often research that is not hypothesis-driven or is simply an extension of well-known, established verified knowledge and no new knowledge is forthcoming. At best, the students being educated in these programs will be trained to simply conduct more of the same research with no significant contribution forthcoming. Rarely does a major advance result from these activities.

Research is also difficult to evaluate when research trends often shift quickly to respond to a pandemic, increasing energy costs and alternative energy forms are being researched, security and military applications, space exploration, communications, or a gov- 
ernment policy decision is implemented to target strategic areas of research or research funding is simply reduced because of massive debts. All areas of basic research are not supported equal.

There is also the situation where researchers and institutions advertise or claim they are world-class institutions of teaching and research, when it is known they are not. Research activities cover the entire spectrum from unacceptable to excellent. Although excellence is often used as a descriptor, it is difficult to measure. Sometimes, excellent research is not publicized and mediocre research is promoted as being world-class and excellent. As time passes, the claimed excellent research may become less important and even be retracted from the journal with a scandal attached to it. Moreover, most researchers do not produce excellent research throughout their entire career, with each year producing better research than the previous year. One or two major contributions during a career is exceptional.

The better approach to research is to collaborate and produce the best research as an individual or as a team, that is possible with the resources available. There will always be a range of skills and quality of research. Self-promotion should be left behind and an engaged and cooperative research environment should be provided where people are supported and nurtured to do their very best as individuals and teams. If the research becomes recognized as excellent contributions in the years ahead, then science and humanity benefit. Otherwise, the attempts to convince the world that excellence is what your institution accomplishes may in fact be an immense distraction from real scholarship that is still difficult to measure in a nonbiased manner. New and improved approaches will be necessary to evaluate complex activities like science research so humans are not distracted by the advertising and marketing of research that is not worldclass, but certainly should be conducted for science and humanity.

It is also wise to reflect upon honoring your science profession through contributions, as this is better than being honored by your profession. Science knowledge is additive, and many small incremental pieces connected correctly may lead to a quantum leap in knowledge and innovation. Consider the evidence accumulated prior to the monumental discovery of the structure of DNA. Reflect on how this discovery has changed the world in ways we still do not completely understand. 